\title{
Amperometric determination of phosphoglucomutase activity with a bienzyme screen-printed biosensor
}

\author{
Yue Cui, * John P. Barford, and Reinhard Renneberg \\ Department of Chemical Engineering and Department of Chemistry, Hong Kong University of \\ Science and Technology, Clear Water Bay, Kowloon, Hong Kong \\ *Corresponding author. Email: kecuiyue@ust.hk
}

Phosphoglucomutase (PGM) is a ubiquitous enzyme that is expressed in all organisms from bacteria to plants to animals and controls a key branch point for carbohydrate metabolism. PGM catalyzes the interconversion of glucose-1-phosphate and glucose-6-phosphate. In this process, the enzyme links various catabolic pathways to yield energy ATP or reducing power NAD(P)H, and several anabolic pathways, such as to lead to the synthesis of polysaccharides [1-4].

Due to its importance, measurements for the enzymatic activity of PGM have been widely performed, by the use of optical methods with coupled enzyme system [3-11], or the use of a combination of ion/molecule reactions and FT-ICR mass spectrometry [12]. However, these measurements either result in a long detection time, a large amount of enzyme consumption, or complex procedures which need to be performed by skilled personnel. The importance of amperometric enzyme-based biosensors has increased considerably in recent years thanks to the advantages of being highly sensitive, rapid, accurate, economical and easy-to-handle for specific measurement of target analyte in complex matrices such as blood, food product and 
environmental sample. To the best of our knowledge, there is no report for the determination of PGM activity using an amperometric biosensor.

In this work, we present an amperometric determination of PGM activity with a bienzyme screen-printed biosensor. As shown in Fig.1, the principle is as follows: Phosphoglucomutase (PGM, EC 5.4.2.2, from rabbit muscle, Sigma) converts glucose-1-phosphate to glucose-6phosphate. Glucose-6-phosphate dehydrogenase (G6PDH, EC 1.1.1.49, from Leuconostoc mesenteroides, Sigma) catalyzes the specific dehydrogenation of glucose-6-phosphate by consuming $\mathrm{NAD}^{+}$. The product, $\mathrm{NADH}$, initiates the irreversible decarboxylation and the hydroxylation of salicylate by salicylate hydroxylase (SHL, EC 1.14.13.1, from Pseudomonas sp., GDS Technology Inc., USA) in the presence of oxygen to produce catechol, which results in a detectable signal due to its oxidation at the working electrode.

The bienzyme electrode for the measurement of PGM activity is based on the detection of glucose-6-phosphate, the product of the PGM-catalyzed reaction. From literature, glucose-6phosphate biosensors have been developed by several methods, including the combinations of G6PDH and various mediators, or the combination of phosphatase and glucose oxidase [13-15]. In this work, the successful coupling of SHL and G6PDH on a screen-printed electrode can also serve as a glucose-6-phosphate biosensor.

A potentiostat EP30 (Biometria, Germany) and a computer installed with the software FIABOLO were used. The screen-printed electrode (BioSensorTrend, Germany) with a 2electrode configuration was composed of a platinum $(\mathrm{Pt})$ working electrode (diameter: $1 \mathrm{~mm}$ ) and an $\mathrm{Ag} / \mathrm{AgCl}$ reference/counter electrode. A measuring cell (volume: $1 \mathrm{ml}$ ), connected to a syringe and installed with two connectors (cathode and anode) and an electrode-fitting site, was 
constructed for experiments.

The screen-printed electrode was covered with a mixture of SHL, G6PDH and glutaraldehyde, followed by drying and storing at $4{ }^{\circ} \mathrm{C}$ overnight. The biosensor was then screwed into the measuring cell, which was filled with buffer solution, and rehydrated for around $1 \mathrm{~h}$ at room temperature to allow the enzyme matrix swelling before usage. Experiments were performed by applying the specific potential for this type of screen-printed electrode at $0.42 \mathrm{~V}$ and magnetically stirring the solution at $300 \mathrm{rpm}$ to obtain a uniform distribution of PGM. The measurement was started by adding PGM into the buffer solution contained in the measuring cell, and the current velocity $\left(\mathrm{nA} \min ^{-1}\right.$ ) was recorded for plotting calibration curve. A syringe was used between each measurement for sucking the buffer solution out of the measuring cell to remove PGM in the solution, and thus to remove catechol on the electrode surface.

A two-steps optimization was needed before the sensor calibration in order to improve the sensor performance for the determination of PGM activity, which was shown in Table 1.

The first step is the optimization of the enzyme matrix, including the enzyme loadings and the immobilization agent concentrations. Various loadings of SHL, G6PDH and glutaraldehyde on screen-printed electrodes were investigated to obtain the maximum current velocity, as shown from Test 1 to Test 7 in Table 1. Based on the optimization, a mixture containing $0.33 \mathrm{U}$ SHL and $1.88 \mathrm{U}$ G6PDH with $1 \%$ glutaraldehyde in $0.5 \mu$ of enzyme matrix was used for further experiments.

The second step was the optimization of the working condition, including $\mathrm{pH}$ value, substrate and cofactor concentrations in the buffer solution. The effects of glucose-1, 6- 
diphosphate and $\mathrm{MgCl}_{2}$ were also studied due to being the activating cofactor and metal cofactor for the PGM-catalyzed reaction. To improve the sensor performance, various loadings of glucose-1-phosphate, salicylate, $\mathrm{NAD}^{+}$, glucose-1, 6-diphosphate, $\mathrm{MgCl}_{2}$, and buffer $\mathrm{pH}$ were investigated, as shown from Test 7 to Test 24 in Table 1. In order to obtain the maximum current velocity for the measurement of PGM activity, the substrate and cofactor concentrations in the buffer solution should be sufficient to avoid the signal saturation due to their inadequate loadings. The optimized working condition obtained was $100 \mathrm{mM}$ Tris-HCl buffer solution containing 5 mM glucose-1-phosphate, $5 \mathrm{mM}$ salicylate, $5 \mathrm{mM} \mathrm{NAD}^{+}, 50 \mu \mathrm{M}$ glucose-1, 6-diphosphate and 5 $\mathrm{mM} \mathrm{MgCl}_{2}$ at $\mathrm{pH} 8.0$.

Fig. 2 shows the calibration curve for PGM activity using the bienzyme screen-printed sensor. The measurements of PGM activities were performed by the biosensor with the optimal enzyme matrix and working condition. As the PGM activity was proportional to the rate of production of glucose-6-phosphate, it was further proportional to the rate of production of catechol and the current velocity, thus current velocity $\left(\mathrm{nA} \min ^{-1}\right.$ ) was used for the determination of PGM activity. As shown in the figure, a linear relationship was obtained between the current velocity and the PGM activity from $0.05 \mathrm{U} \mathrm{ml}^{-1}$ to $5 \mathrm{U} \mathrm{ml}^{-1}$ with a detection limit of $0.02 \mathrm{U} \mathrm{ml}^{-1}$ (slope: $\left.76.36(\mathrm{nA} \mathrm{min}-1) /\left(\mathrm{U} \mathrm{ml}^{-1}\right), \mathrm{R}^{2}=0.9988, \mathrm{n}=3\right)$. The linear detection range and detection limit are decided by the recording method, and if the record of current velocity is changed from $\mathrm{nA} \min ^{-1}$ to $\mathrm{nA}(2 \mathrm{~min})^{-1}$ or $\mathrm{nA}(3 \mathrm{~min})^{-1}$, the linear detection range and detection limit will be changed and improved.

Also, the sensor has a fast measuring time $(1 \mathrm{~min})$ and a short recovery time $(2 \mathrm{~min})$ with high reproducibility. Hence, the total measurement of PGM activity takes less than 4 min with 
simple operations, which is more rapid and convenient than conventional methods.

In summary, we have demonstrated the measurement for the enzymatic activity of PGM using an amperometric screen-printed biosensor based on the co-immobilization of SHL and G6PDH. The sensor shows high performance characteristics with a broad detection range (0.05-5 $\left.\mathrm{U} \mathrm{ml}^{-1}\right)$ and a rapid measuring time $(1 \mathrm{~min})$. Thus, we provide a new analytical approach to the determination of PGM activity rapidly, sensitively, economically and easy to handle.

\section{Acknowledgements}

The authors gratefully acknowledge Hong Kong Research Grant Council (HKUST625302P and 510-0091-02-44000-0) for the financial support.

\section{References}

[1] W.J. Ray, E.J. Peck, Phosphoglucomutase, in: P.D. Boyer (Ed.), The Enzymes, third ed., Academic Press, New York and London, 1972, pp. 408-458.

[2] A. Lytoychenko, L. Sweetlove, M. Pauly, A.R. Fernie, The influence of cytosolic phosphoglucomutase on photosynthetic carbohydrate metabolism, Planta 215 (2002) 10131021.

[3] J.I. Akutsu, Z. Zhang, M. Tsujimura, M. Sasaki, M. Yohda, Y. Kawarabayasi, Characterization of a thermostable enzyme with phosphomannomutase / phosphoglucomutase activities from the hyperthermophilic archaeon Pyrococcus horikoshii 
OT3, J. Biochem.138 (2005) 159-166.

[4] L.R. Mesak, M.K. Dahl, Purification and enzymatic characterization of PgcM: a $\beta$ phosphoglucomutase and glucose-1-phosphate phosphodismutase of Bacillus subtilis, Arch. Microbiol. 174 (2000) 256-264.

[5] G.F. Zhang, J.Y. Dai, L.B. Wang, D. Dunaway-Mariano, L.W. Tremblay, K. N. Allen, Catalytic Cycling in $\beta$-Phosphoglucomutase: A Kinetic and Structural Analysis, Biochemistry 44 (2005) 9404-9416.

[6] H. Inoue, S. Kondo, Y. Hinohara, N. Juni, D.Yamamoto, Enhanced phosphorylation and enzymatic activity of phosphoglucomutase by the Btk29A tyrosine kinase in Drosophila, Arch. Biochem. Biophys. 413 (2003) 207-212.

[7] P.A. Videira, L.L. Cortes, A.M. Fialho, I. Sá-Correia, Identification of the pgmG gene, encoding a bifunctional protein with phosphoglucomutase and phosphomannomutase activities, in the gellan gum- producing strain Sphingomonas paucimobilis ATCC 31461, Appl. Environ. Microb. 66 (2000) 2252-2258.

[8] D.M. Frazier, E.H. Clemons, H.N. Kirkman, Minimizing false positive diagnoses in newborn screening for galactosemia, Biochem. Med. Metab. B. 48 (1992) 199-211.

[9] L.I. Sergeeva, D. Vreugdenhil, In situ staining of activities of enzymes involved in carbohydrate metabolism in plant tissues, J. Exp. Bot. 53 (2002) 361-370. 
[10] S.C. Howard, S.J. Deminoff, P.K. Herman, Increased phosphoglucomutase activity suppresses the galactose growth defect associated with elevated levels of Ras signaling in S-cerevisiae, Curr. Genet. 49 (2006) 1-6.

[11] C.A. Masuda, M.A. Xavier, K.A. Mattos, A. Galina, M. Monterolomeli, Phosphoglucomutase is an in vivo lithium target in yeast, J. Biol. Chem. 276 (2001) 3779437801.

[12] H. Gao, J.A. Leary, Kinetic measurements of phosphoglucomutase by direct analysis of glucose-1-phosphate and glucose-6-phosphate using ion/molecule reactions and Fourier transform ion cyclotron resonance mass spectrometry, Anal. Biochem. 329 (2004) 269-275.

[13] A.S. Bassi, D. Tang, M.A. Bergougnou, Mediated, amperometric biosensor for glucose-6phosphate monitoring based on entrapped glucose-6-phosphate dehydrogenase, $\mathrm{Mg}^{2+}$ ions, tetracyanoquinodimethane, and nicotinamide adenine dinucleotide phosphate in carbon paste, Anal. Biochem. 268 (1999) 223-228.

[14] C.H. Tzang, R. Yuan, M. Yang, Voltammetric biosensors for the determination of formate and glucose-6-phosphate based on the measurement of dehydrogenase-generated NADH and NADPH, Biosens. Bioelectron. 16 (2001) 211-219.

[15] F. Mazzei, F. Botre, C. Botre, Acid phosphatase/glucose oxidase-based biosensors for the determination of pesticides, Anal. Chim. Acta 336 (1996) 67-75. 


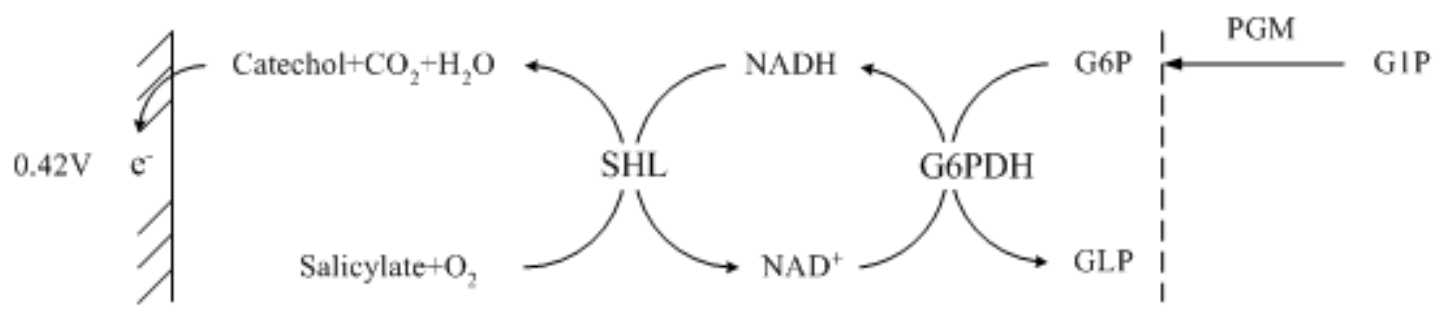

Fig.1. Schematic illustration of the amperometric screen-printed biosensor for the determination of PGM activity (G1P: glucose-1-phosphate; G6P: glucose-6-phosphate; GLP: D-glucono-1, 5lactone 6-phosphate; PGM: phosphoglucomutase; G6PDH: glucose-6-phosphate dehydrogenase; SHL: salicylate hydroxylase). 


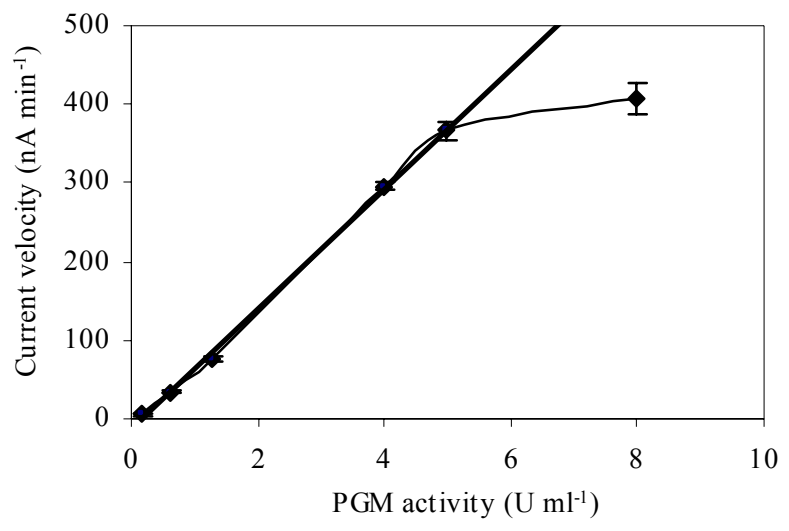

Fig.2. Calibration curve for PGM activity using the amperometric screen-printed biosensor (Sensor: $0.33 \mathrm{U}$ SHL, $1.88 \mathrm{U}$ G6PDH with $1 \%$ glutaraldehyde in $0.5 \mu$ of enzyme matrix. Buffer: $100 \mathrm{mM}$ Tris- $\mathrm{HCl}$ buffer containing $5 \mathrm{mM}$ glucose-1-phosphate, $5 \mathrm{mM}$ salicylate, $5 \mathrm{mM} \mathrm{NAD}^{+}$, $50 \mu \mathrm{M}$ glucose-1, 6-diphosphate and $5 \mathrm{mM} \mathrm{MgCl}_{2}$ at $\mathrm{pH}$ 8.0). 
Table 1

Optimization of the enzyme matrix and working condition

\begin{tabular}{|c|c|c|c|c|c|c|c|c|c|c|}
\hline Test & (U) & G6PDH & $(\%)$ & $(\mathrm{mM})$ & Salicylate & $(\mathrm{mM})$ & $\mathrm{G} 1,6 \mathrm{diP} \mathrm{P}^{\mathrm{b}}$ & $\begin{array}{l}\mathrm{MgCl}_{2} \\
(\mathrm{mM})\end{array}$ & $\mathrm{pH}$ & $\begin{array}{l}\text { Relative current } \\
\text { velocity }(\%)^{\mathrm{c}}\end{array}$ \\
\hline 1 & 0.33 & 0.94 & 1.00 & 5 & 5 & 5 & 50 & 5 & 8 & $68.6 \pm 1.0$ \\
\hline 2 & 0.33 & 1.41 & 1.00 & 5 & 5 & 5 & 50 & 5 & 8 & $96.5 \pm 2.0$ \\
\hline 3 & 0.17 & 1.88 & 1.00 & 5 & 5 & 5 & 50 & 5 & 8 & $73.0 \pm 1.5$ \\
\hline 4 & 0.50 & 1.88 & 1.00 & 5 & 5 & 5 & 50 & 5 & 8 & $98.9 \pm 1.8$ \\
\hline 5 & 0.33 & 1.88 & 0.67 & 5 & 5 & 5 & 50 & 5 & 8 & $98.1 \pm 1.7$ \\
\hline 6 & 0.33 & 1.88 & 1.33 & 5 & 5 & 5 & 50 & 5 & 8 & $56.4 \pm 0.3$ \\
\hline 7 & 0.33 & 1.88 & 1.00 & 5 & 5 & 5 & 50 & 5 & 8 & $100.0 \pm 1.9$ \\
\hline 8 & 0.33 & 1.88 & 1.00 & 0 & 5 & 5 & 50 & 5 & 8 & $0.0 \pm 0.0$ \\
\hline 9 & 0.33 & 1.88 & 1.00 & 2 & 5 & 5 & 50 & 5 & 8 & $99.8 \pm 2.2$ \\
\hline 10 & 0.33 & 1.88 & 1.00 & 10 & 5 & 5 & 50 & 5 & 8 & $98.2 \pm 3.2$ \\
\hline 11 & 0.33 & 1.88 & 1.00 & 5 & 0 & 5 & 50 & 5 & 8 & $9.8 \pm 0.8$ \\
\hline 12 & 0.33 & 1.88 & 1.00 & 5 & 2 & 5 & 50 & 5 & 8 & $97.1 \pm 3.0$ \\
\hline 13 & 0.33 & 1.88 & 1.00 & 5 & 10 & 5 & 50 & 5 & 8 & $99.9 \pm 3.6$ \\
\hline 14 & 0.33 & 1.88 & 1.00 & 5 & 5 & 0 & 50 & 5 & 8 & $0.0 \pm 0.0$ \\
\hline 15 & 0.33 & 1.88 & 1.00 & 5 & 5 & 2 & 50 & 5 & 8 & $97.5 \pm 2.2$ \\
\hline 16 & 0.33 & 1.88 & 1.00 & 5 & 5 & 10 & 50 & 5 & 8 & $100.0 \pm 3.6$ \\
\hline 17 & 0.33 & 1.88 & 1.00 & 5 & 5 & 5 & 0 & 5 & 8 & $20.2 \pm 0.6$ \\
\hline 18 & 0.33 & 1.88 & 1.00 & 5 & 5 & 5 & 20 & 5 & 8 & $98.3 \pm 1.6$ \\
\hline 19 & 0.33 & 1.88 & 1.00 & 5 & 5 & 5 & 100 & 5 & 8 & $96.7 \pm 3.3$ \\
\hline 20 & 0.33 & 1.88 & 1.00 & 5 & 5 & 5 & 50 & 0 & 8 & $21.8 \pm 1.2$ \\
\hline 21 & 0.33 & 1.88 & 1.00 & 5 & 5 & 5 & 50 & 2 & 8 & $76.4 \pm 3.3$ \\
\hline 22 & 0.33 & 1.88 & 1.00 & 5 & 5 & 5 & 50 & 10 & 8 & $96.6 \pm 2.9$ \\
\hline 23 & 0.33 & 1.88 & 1.00 & 5 & 5 & 5 & 50 & 5 & 7 & $73.9 \pm 2.2$ \\
\hline 24 & 0.33 & 1.88 & 1.00 & 5 & 5 & 5 & 50 & 5 & 9 & $75.2 \pm 1.6$ \\
\hline
\end{tabular}

${ }^{\mathrm{a}} \mathrm{GA}$ : glutaraldehyde.

${ }^{\mathrm{b}} \mathrm{G} 1$, 6diP: glucose-1, 6-diphosphate.

${ }^{\mathrm{c}}$ The relative current velocity (\%) was calculated by normalizing the current velocity of the test to the maximum current velocity obtained from test 7 in measuring the PGM activity of $5 \mathrm{U} \mathrm{ml}^{-1}(\mathrm{n}=3)$. 